\title{
Historical masonry churches diagnosis supported by an analytic-hierarchy-process-based decision support system
}

\author{
Valentino Sangiorgio ${ }^{1}$, Silvia Martiradonna ${ }^{1,2}$, Fabio Fatiguso ${ }^{1}$, Giuseppina Uva ${ }^{1}$ \\ 1 Politecnico di Bari, Dept. DICATECh, Via Orabona 4 Bari 70128, Italy \\ 2 Univerdisad de Cantabria, Dept. Ingeniería Estructural y Mecánica, Av. De los Castros 44 Santander 39005, Spain
}

\begin{abstract}
The structural and anti-seismic performances of historical masonry churches are related not only to structural damage and masonry quality but also to other criticalities that can jeopardise the connections, wooden elements, and non-structural elements. As such, the technical and scientific communities are interested in the development of fast visual-survey approaches for assessing these issues and for performing exhaustive diagnostics by considering all the parameters affecting the building performance.

In this paper, a new procedure for performing rapid visual surveys and the diagnostics of masonry buildings using a set of condition ratings is proposed. The proposed novel approach includes three synergistically related techniques: i) the analytic hierarchy process method for measuring and analysing both qualitative and quantitative data during a visual survey, ii) a suitable survey form to perform a rapid visual inspection implementable in a decision support system (DSS), and iii) a DSS procedure to provide a powerful computerised tool that would be useful in large-scale data acquisition. Finally, to demonstrate the potential of the proposed approach, the Romanesque masonry church SS. Salvatore in Capurso, Italy, is analysed. A comparison with a standard diagnostic workflow is also presented to validate the procedure and to emphasise the advantages of the novel diagnostics.
\end{abstract}

\section{Section: RESEARCH PAPER}

Keywords: Historical masonry churches; Structural performance; Analytic Hierarchy Processes; Decision Support System.

Citation: Valentino Sangiorgio, Silvia Martiradonna, Fabio Fatiguso, Giuseppina Uva, Historical masonry churches diagnosis supported by an analytichierarchy-process-based decision support system, Acta IMEKO, vol. 10, no. 1, article 3, March 2021, identifier: IMEKO-ACTA-10 (2021)-01-03

Editor: Eulalia Balestrieri, University of Sannio, Italy

Received March 19, 2020; In final form October 26, 2020; Published March 2021

Copyright: This is an open-access article distributed under the terms of the Creative Commons Attribution 3.0 License, which permits unrestricted use, distribution, and reproduction in any medium, provided the original author and source are credited.

Funding: This work was supported by the project manufacturing education and training governance model for Industry 4.0 in the Adriatic-lonian area Future 4.0 Adriatic-Ionian Programme Interreg V-B Transnational 2014-2020.

Corresponding author: Valentino Sangiorgio, e-mail: valentino.sangiorgio@poliba.it

\section{INTRODUCTION}

The structural diagnostics of a masonry building should involve numerous criteria, phenomena, and criticalities. The process of knowledge starts from an in-depth investigation of various different aspects of the construction, including the building history (expansion interventions, transformations, traumatic events), the geometry, the technology used, and the characteristics of the materials as well as any degradation, cracking, or deformation. The synthesis of this information allows us to better understand the structural behaviour and to formulate a valid diagnosis, highlighting the potential weaknesses, collapse mechanisms, instability, and degradation of the structure.

Masonry churches are the category of buildings most vulnerable to catastrophic events, often experiencing serious damage and collapses as a result of the earthquakes that have occurred throughout history and have compromised the structural performance of the buildings [1].

The difficulty in analysing masonry building degradation is related to the heterogeneity of the factors that pertain to the building's residual performance evaluation.

As a multicriteria decision-making tool, the analytic hierarchy process (AHP) allows for performing exhaustive structural analyses due to the possibility of considering numerous criteria and subsequently affording them a calibrated weight.

This method has become popular in various areas of construction. Starting from the project stage, both Fong and Choi [2] and Hsieh et al. [3] used the AHP approach to identify the key selection criteria for determining the contractor selection, Plebankiewiczm and Kubek [4] and Kahraman et al. [5] for selecting the best material supplier, and Wong and $\mathrm{Li}$ [6] for analysing the selection among the various intelligent building 
systems. The AHP method has also been used for the systematic evaluation of various factors, including building efficiency, safety, user comfort, reliability, functionality, and maintainability. In addition, it has been employed to characterise the design work, to evaluate the soft benefits in relation to the costs [7], [8], and to estimate the environmental work impact [9], [10]. Meanwhile, Teo and Ling [11] and Li et al. [12] used the AHP approach to evaluate the safety and administration of work sites, while Das et al. [13], Wu et al. [14], and Kettner and Diaz [15] used it in relation to construction management, and Ali and Nsairat [16] and Chang et al. [10] used it to estimate green building ratings.

In terms of existing buildings, the approach presents an effective assessment tool for supporting building energy rehabilitation [17], [18], performing large-scale structural vulnerability analysis [19], and identifying the criticalities in seismic and volcanic vulnerability assessments [20], [21].

Furthermore, the AHP approach has proven useful in scheduling the building maintenance and selecting the most suitable intervention alternatives [22], since it allows for comparing multiple measures such as attribute data and both qualitative and quantitative data [13]. Meanwhile, Sangiorgio et al. [23] employed the approach as part of a decision support system (DSS) during the performance monitoring phase, which involved a combination of the AHP method with various information technologies. Here, the authors obtained data weighted via AHP in order to evaluate the building conditions.

Cultural heritage monitoring and preservation is a developing discipline that consists of the application of intelligent technologies in cultural sites. At present, such technologies are widely used to monitor different parameters, such as the thermohygrometric conditions [23], [24], the light, and the air quality of churches, to help preserve the wall paintings and architectural monuments [25], [26], [27], [28], while they are also employed to estimate accelerations, tensile stresses, compressive stresses, and the degradation of building materials [29], [30].

Numerous parameters must be considered to obtain a complete overview of the performance of masonry churches, with the masonry quality, cracking patterns, connections, or wood elements just some of the parameters that must be analysed to obtain an exhaustive preliminary structural diagnostic of such churches.

In this paper, the AHP approach [31] is used to comprehensively study the characteristics involved in the performance of masonry structures and to establish a novel visual-survey-based methodology to measure both quantitative and qualitative data and to perform the relevant diagnostics.

A key point of the proposed method is the effective evaluation of suitable condition ratings, which depend on an extremely large amount of possible damage, degradations, or criticalities affecting the church. In this field, the use of the AHP approach can be particularly useful since it allows for considering both qualitative and quantitative data and for examining complex issues via multicriteria analysis. The resulting condition ratings can then be easily implemented in a DSS that supports the decision-making activities related to maintenance and monitoring [32].

\section{THE ANALYTIC-HIERARCHY-PROCESS-BASED METHODOLOGY}

The AHP methodology, used to quantify the weights of the macro-element collapse modes, is based on Saaty's well-known three-step method [31], which involves i) hierarchically

\begin{tabular}{c|cccc}
$\mathrm{A}$ & 1 & 2 & $\ldots$ & $n$ \\
\hline 1 & 1 & $1 / a_{1,2}$ & $\ldots$ & $1 / a_{1, n}$ \\
2 & $1 / a_{1,2}$ & 1 & $\ldots$ & $1 / a_{2, n}$ \\
$\ldots$ & $\ldots$ & $\ldots$ & 1 & $\ldots$ \\
$n$ & $1 / a_{1, n}$ & $1 / a_{2, n}$ & $\ldots$ & 1
\end{tabular}

Figure 1. The generic matrix of judgments $A$.

structuring the problem, ii) a weight evaluation, and iii) a summary of the priority. Starting with a decision issue, the first step consists of structuring the problem according to a hierarchical scheme to identify the macro- and sub-criteria. Meanwhile, the second step, the weight evaluation, presents the core of the method and provides the weights necessary to generate the ranking. In this step, it is possible to analyse each aspect of the decision issue individually by considering ordered criteria and by performing pair comparisons using Saaty's fundamental scale (Table 1 ). The result is a $n \times n$ judgments matrix A (Figure 1).

In terms of solving an eigenvector issue, the AHP approach allows for determining the relevant weights. In addition, Saaty's method involves defining the consistency ratio (CR) to verify the coherence of the assigned judgement and the reliability of the results [31]. According to the various empirical studies conducted by Saaty, a CR of $<0.10$ can be regarded as acceptable [31]-[33].

Finally, the third step, summarising the priority, is performed to determine the global ranking and weight. These are obtained by multiplying each criterion weight by the alternative weight and by summing the results for each alternative.

\section{APPLICATION OF THE ANALYTIC HIERARCHY PROCESS APPROACH}

The proposed approach is particularly useful in terms of providing an exhaustive overview of the issues potentially affecting a masonry church. In addition, numerous aspects and criteria, both qualitative and quantitative, can be considered within the diagnostics structure. The main advantages of the proposed approach are the simplicity of the measurements, the affordability of the survey, and the possibility of obtaining a complete overview of the criticalities and an adequate 'history' of the previous surveys by implementing the approach in a DSS. Meanwhile, while specific investigations performed using thermal imaging cameras or ground-penetrating radar can provide a higher level of information (e.g. cracks not visible to the human eye), this type of survey is more time consuming and is rarely applicable to the entire structure. As such, the two approaches can be regarded as complementary. First, the proposed DSS approach can be applied at a large scale to identify the components of masonry churches that require further

Table 1. Saaty's fundamental scale [31].

\begin{tabular}{ll}
\hline $\boldsymbol{a}_{i j}$ & \multicolumn{1}{c}{ Verbal scale } \\
\hline$a_{i j}=1$ & Equal importance \\
$a_{i j}=3$ & Moderate importance of one over another \\
$a_{i j}=5$ & Strong importance \\
$a_{i j}=7$ & Very strong importance \\
$a_{i j}=9$ & Extreme importance \\
$1.5-4-6-8$ & Intermediate value \\
$1 / 9,1 / 8, \ldots ., 1 / 2$ & The reciprocal expresses an opposite judgement \\
\hline
\end{tabular}


investigation. Second, more in-depth surveys using thermal imaging cameras or ground-penetrating radar can be carried out

\subsection{Step 1: the issue of masonry damage and quality}

The first step of the AHP approach was applied to investigate the deterioration in the structural performance of masonry churches that is due to the various phenomena and typologies pertaining to construction criticalities and damage. Specifically, three macro-criteria were considered: A) the masonry performance, B) the effectiveness of the connections, and C) the conservation state of the wooden flooring.

A) The first macro-criterion, used to determine the structural performances, relates to the quality of the masonry. Here, the following five sub-criteria were considered, as shown in Figure 2.

i) The first sub-criterion classifies the macro elements of the churches by considering the recurrent failure mechanisms. The macro elements are as follows: chamber, façade, chapel, roof, transept, apse, bell tower, dome, and triumphal arches (indicated in blue in Figure 2).

ii) The second sub-criterion relates to the damaged elements. It is worth noting that recent post-earthquake observations in Italy (i.e. Umbria and Marche, 1997; L'Aquila, 2009; Emilia, 2012; Central Italy, 2016) revealed different levels of vulnerability depending on the damaged building components [34]. The relevant elements here include walls, pillars, columns, arches, vaults, architraves, floor strips, and ribs.

iii) The third fundamental criterion exploits an existing methodology known as the masonry quality index (MQI) method. This method is both effective and perfectly compatible with the AHP approach and was thus incorporated into our AHP methodology. The MQI method involves evaluating the presence, the partial presence, or the absence of certain parameters that define the 'rule of the art', that is, a set of construction devices that, if executed during the wall construction, provide good behaviour and ensure both compactness and a monolithic quality. In such an approach, a visual procedure is used to classify the masonry on the basis of a direct measurement of a specific group of parameters (i.e. stone properties [SM], stone dimensions [SD], stone shape [SS], wall leaf connections [WC], horizontal bed joints [HJ], vertical joints $[\mathrm{VJ}]$, and mechanical properties [MM]) before, finally, the MQI is evaluated through the various tabulated values.

iv) The fourth criterion relates to the masonry performance in terms of cracking or any criticality manifestations affecting the building. Here, it is necessary to take into account the type of damage affecting each church element in order to perform exhaustive diagnostics. In addition, the classification of the damage must be established according to the model devised by Sangiorgio et al. [35]. In this approach, the types of building damage are decomposed and coded on the basis of crack type (vertical, oblique, etc.), with each crack-type then further classified in terms of the severity of the damage (magnitude A, B or $\mathrm{C}$, where $\mathrm{C}$ is the most severe damage).

v) Finally, the sub-criterion, criticality manifestation, is considered in terms of identifying any masonry deformation, scroll back, or disconnection.

B) The second macro-criterion relates to the efficiency of the connections and is also classified in terms of various sub-criteria as follows: vi) tie rods anchor systems, (vii) relative corrosion, viii) wall-to-floor connections, and ix) wall-to-wall connections. These aspects ensure the continuity of the energy path and prevent the occurrence of the majority of local collapse mechanisms. In fact, the out-of-plane behaviour of masonry walls observed in recent seismic events has demonstrated the critical importance of having appropriate connections in historical buildings.

C) The third macro-criterion relates to the conservation state of the wood flooring. The evaluation of the quality and degradation of the wooden elements begins with a macroscopic examination that allows for the identification of the characteristics of the wood, such as colour, grain, and texture, as well as any anatomical characteristics. Specifically, the following wood flooring qualities are considered in the evaluation of the overall performance of masonry buildings: $\mathrm{x}$ ) the typology of the damaged element (e.g. timber truss or slab), xi) the wood criticality related to moisture, xii) surface alteration, xiii) extension of the problem, and xiv) any mechanical problem including cracks or xv) deformations.

Finally, a suitable classification of the wood quality is used to take into account the natural vulnerability of the material in terms of xvi) knotting and xvii) shrinkage.

\subsection{Step 2: weight evaluation}

The second step in the AHP involves analysing each aspect of the structure of the problem individually in order to weight the criteria and parameters involved.

This section refers to previous studies related to every aspect of masonry structures to obtain the judgment matrices. Here, seven matrices were used to analyse the sub-criteria and parameters of the masonry macro-criteria, with five matrices evaluated to obtain the criteria and parameters weights of the connections macro-criterion, and eight matrices estimated to provide the weights related to the wood flooring macro-criterion.

To provide an example, the weight calculations of the tie rod anchor system related to the connections macro-criterion is

\section{MASONRY BUILDING PERFORMANCES}

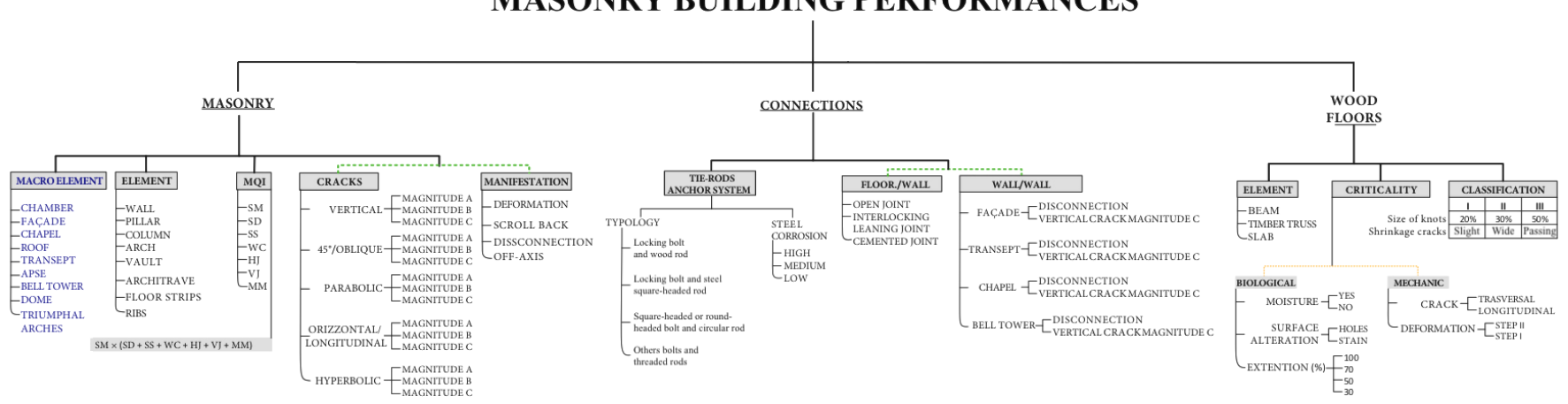

Figure 2. Structure of the problem: historical masonry church diagnostics. 


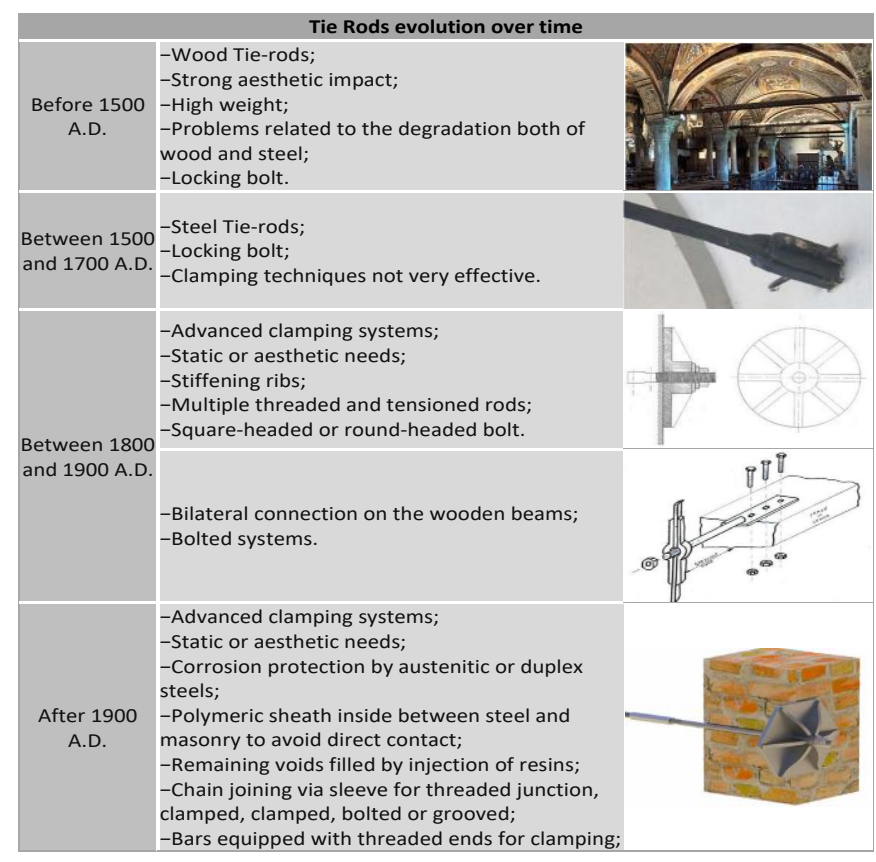

Figure 3. Study of tie rod evolution over time.

provided. In fact, the effectiveness of the tie rods is related to the typology (classified by year of manufacture) and the level of steel corrosion, as discussed in the structuring of the problem. Figure 3 shows the preliminary study and classification of the main tie rod typologies.

By referring to the preliminary study, pairwise comparisons of the alternatives were carried out as well as qualitative analysis to obtain the judgment matrix. The weights were obtained by solving the eigenvector problem defined by Saaty [31].

The resulting matrix satisfies the $\mathrm{CR}$ requirement $(C R<0.1)$, meaning it was possible to derive consistent weights, all normalised between 0 and 1 (see Table 2).

It is worth noting that the typology of the tie rods was combined with their state of conservation to ensure a precise evaluation of the performance. In fact, this second parameter, steel corrosion, classifies the condition in terms of three alternatives: low, medium, and high. Meanwhile, a qualitative evaluation was performed to quantify the influence of corrosion on the tie rod performance based on the detailed studies contained in the existing literature.

The condition ratings could be defined following the weighting phase. This operation relates to the third step of the summary of priority. The condition rating formulas were obtained by multiplying each criterion weight by the sub-criteria weight and subsequently summing the results, as in the standard AHP procedure. For this purpose, three condition ratings were

Table 3. Connections, macro-criteria, and weights.
Table 2. Judgment matrix for tie rod typology parameters, weights, and CRs.

\begin{tabular}{lcccccc}
\hline \multicolumn{1}{c}{ Typology } & a & b & c & d & CR & $\boldsymbol{w}_{6,1}$ \\
\hline Before 1500 (a) & 1.0 & 1.8 & 2.5 & 3.0 & & 1.00 \\
Between 1500-1800 (b) & 0.6 & 1.0 & 2.0 & 2.8 & & 0.69 \\
Between 1800-1900 (c) & 0.4 & 0.5 & 1.0 & 1.9 & 0.01 & 0.41 \\
After 1900 (d) & 0.3 & 0.4 & 0.5 & 1.0 & & 0.26 \\
\hline
\end{tabular}

defined: masonry index $\left(I_{\mathrm{M}}\right)$, connection index $\left(I_{\mathrm{C}}\right)$, and wood elements index $\left(I_{\mathrm{W}}\right)$.

To provide an example, the $I_{\mathrm{M}}$ could be obtained by using the weights obtained in step 2 of the AHP. Table 3 shows the association of the criterion, sub-criterion, or alternative with the relative weights obtained via the comparison matrices, while a complete overview of the tabulated weights is available in the supplementary material (Figure S1).

Let us assume we have surveyed a certain component of the church, one pertaining to a specific macro-element and one that exhibits a specific combination of MQI, cracking, and manifestation. Here, the condition rating for quantifying the performance of the masonry criterion $\left(I_{M}\right)$ could be evaluated using the following equation in accordance with Sangiorgio et al. (2019):

$$
\begin{gathered}
I_{\mathrm{M}}=v_{1} \cdot w_{1, j}+v_{2} \cdot w_{2, j}+v_{3} \cdot\left[w _ { 3 , 1 } \cdot \left(\sum_{j=2}^{7} w_{3, j}\right.\right. \\
\left.\left.\cdot w_{3, j, k}\right)\right]+v_{4} \cdot w_{4, j} \cdot w_{4, j, k}+v_{5} \cdot w_{5, j}
\end{gathered}
$$

where $v_{i}$ is the weights associated with the sub-criteria and $w_{i j}$ is the weights correlated with the parameters of the analysis. Meanwhile, it was possible to evaluate the performances of the connections. Here, the connection index $\left(I_{C}\right)$ could be evaluated using the following formula:

$$
I_{\mathrm{C}}=v_{6} \cdot w_{6, j}+\ldots+v_{9} \cdot w_{9 j} \cdot w_{9, j, k} \cdot
$$

The wood flooring index $\left(I_{W}\right)$ could then be evaluated using the following formula.

$$
I_{\mathrm{W}}=v_{10} \cdot w_{10, j}+v_{11} \cdot w_{11, j}+\ldots+v_{17} \cdot w_{17, j} .
$$

Finally, the overall condition rating (global index: ISTRUCTURE) could be evaluated, with the average of the $I_{\mathrm{M}}, I_{\mathrm{C}}$, and $I_{\mathrm{W}}$ values calculated for all the components of the structure [36].

\section{INTEGRATION OF ANALYTIC-HIERARCHY-PROCESS-BASED APPROACH IN A DECISION SUPPORT SYSTEM}

The proposed approach can be easily exploited to create a spreadsheet that would prove useful to conducting a rapid survey

\begin{tabular}{|c|c|c|c|c|c|c|c|c|}
\hline \multirow{2}{*}{$\begin{array}{c}\text { Criterion } \\
\text { Sub-criterion }\end{array}$} & \multicolumn{8}{|c|}{ CONNECTIONS } \\
\hline & TIE-RODS TYPOLOGY & $v_{6}$ & TIE-RODS STEEL CORROSION & $v_{7}$ & FLOOR/WALL & $v_{8}$ & WALL/WALL & $v_{9}$ \\
\hline \multirow{6}{*}{ Parameters } & Locking bolt and wood rod & $w_{6,1}$ & $\mathrm{HIGH}$ & $w_{7,1}$ & OPEN JOINT & $w_{8,1}$ & FAÇADE & $w_{9,1}$ \\
\hline & $\begin{array}{l}\text { Locking bolt and steel square- } \\
\text { headed rod }\end{array}$ & $w_{6,2}$ & MEDIUM & $w_{7,2}$ & $\begin{array}{l}\text { INTERLOCKING } \\
\text { LEANING JOINT }\end{array}$ & $w_{8,2}$ & TRANSEPT & $\mathbf{w}_{9,2}$ \\
\hline & $\begin{array}{l}\text { Square-headed or round- } \\
\text { headed bolt and circular rod }\end{array}$ & $w_{6,3}$ & LOW & $w_{7,3}$ & CEMENTED JOINT & $w_{8,3}$ & CHAPEL & $\boldsymbol{W}_{9,3}$ \\
\hline & Other bolts and threaded rods & $w_{6,4}$ & & & & & BELL TOWER & $w_{9,4}$ \\
\hline & & & & & & & DISCONNECTION & $w_{9, j, 1}$ \\
\hline & & & & & & & VERTICAL CRACK C & $\boldsymbol{w}_{9, j, 2}$ \\
\hline
\end{tabular}
of a historical church. Here, an appropriate survey form was developed, and a suitable flowchart was produced to explain the DSS process better. 


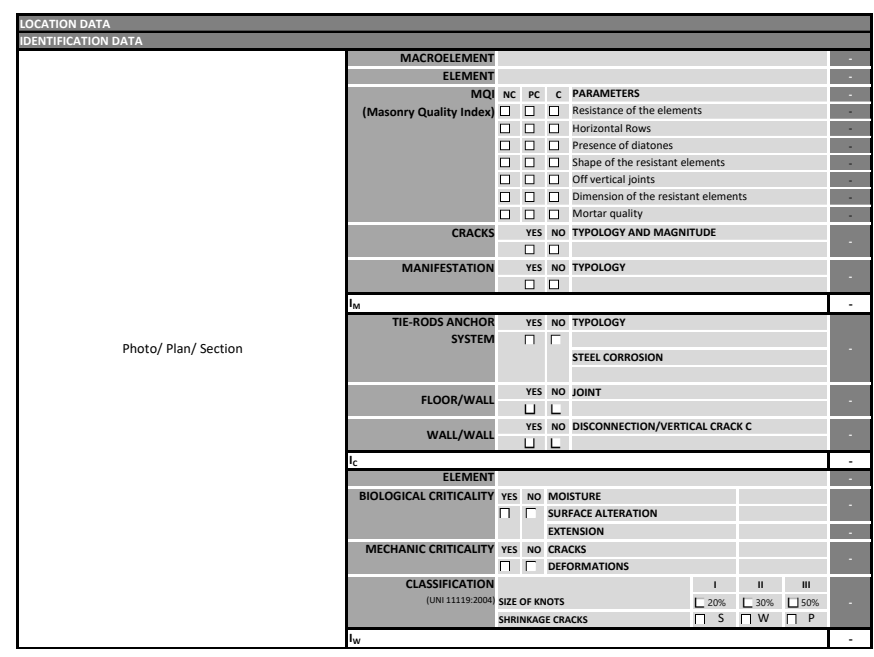

Figure 4. General survey form.

\subsection{Survey form}

A crucial point of the proposed approach is the definition of the survey form that can be implemented in an app for smart devices. Such a spreadsheet-style form allows the user (technicians) to measure and evaluate both qualitative and quantitative data during a fast on-site inspection.

In fact, the condition ratings can be obtained using Eqs. 1-3. Here, the proposed app can be used for detecting any damaged or degraded element of the structure to obtain a numerical evaluation of its condition by taking into account all of the macro-criteria, sub-criteria, and parameters of the considered AHP issue. Figure 4 shows a general survey form (empty form).

\subsection{Decision support system architecture}

The architecture of the proposed DSS consists of five components (Figure 5):

i) The survey form consisting of a suitable spreadsheet that can be implemented in an app for smart devices.

iii) A data management system (DMS), which collects the information provided by the users through the survey form.

iii) A web-based platform that represents the intelligence of the system. This platform processes the survey form data, classifies the church's components, and calculates the condition ratings.

iv) A web application used by technicians to display the reported survey form history and the register information related to the church.

v) An application programming interface (API) connecting the survey form (app) and the web application with the webbased platform and the DMS.

\subsection{Decision support system process}

In order to better specify the DSS procedure and the use of the survey form, a suitable flowchart [37] was produced in accordance with the UML framework (Figure 6). Here, the rules and tasks of the actors involved in the process are highlighted. The flowchart procedure explains all the interactions between the two main components of the DSS (i.e. the survey form implemented in smart devices and the web application), and the actors involved in the process (i.e. the users of the survey form and the bridge technicians and engineers). The flow is described by defining three phases of the process: the data acquisition phase, the data processing phase, and the diagnostic phase.

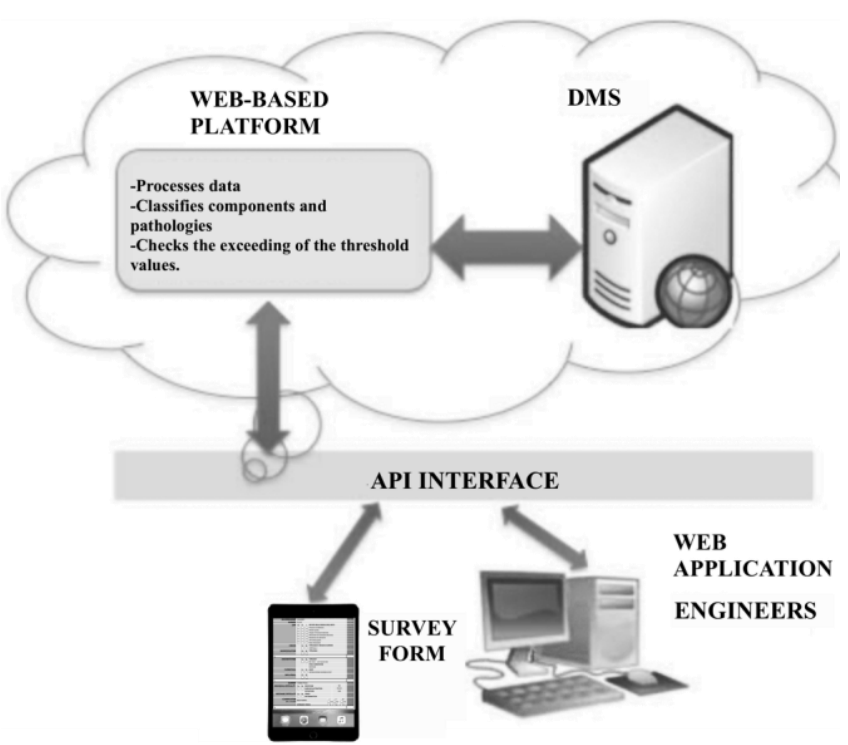

Figure 5. Components of the DSS architecture.

i) During the data acquisition phase, the user first accesses the list of churches on the web-based platform to select those to be surveyed (if the tool is used on a territorial scale, a number of churches can be selected by using a drop-down list). Second, the user can ask to use the survey form for the inspection. Third, the user can complete the inspection by taking photographs of any damage and criticalities before sending the inspection information to the platform.

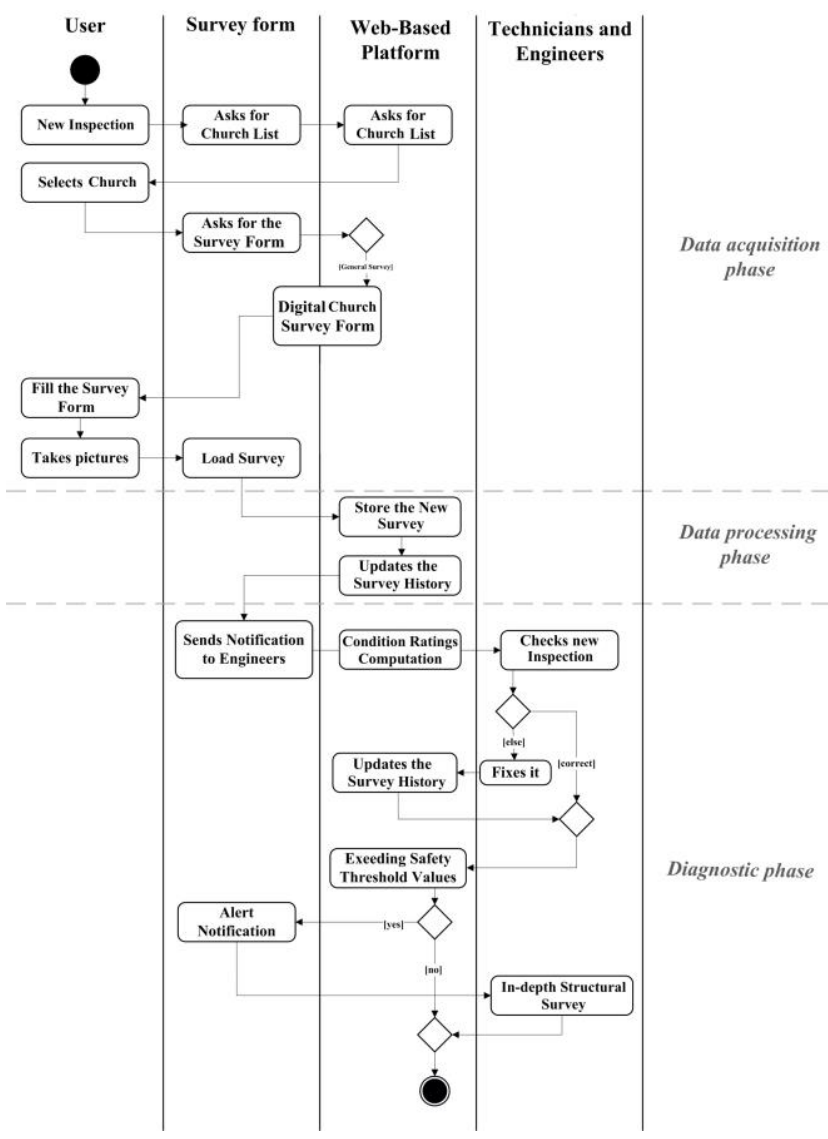

Figure 6. Flowchart explaining the procedure of the system. 
ii) In the data processing phase, the web-based platform uses the received surveys to store the new data and to update the survey's history.

iii) During the diagnostic phase, the web-based platform sends notification of any new damage to the building staff who can read, change, or validate the inspection. At this point, the system is able to automatically evaluate the condition ratings using Eqs. 5-7 and the tabulated weights obtained via the AHP method. Finally, if the condition rating exceeds certain defined threshold values, a suitable alarm protocol is triggered. An alert notification is then sent to all users of the DSS to set up an emergency intervention.

\section{CASE STUDY}

A representative example of a church with a typical Apulian architectural style, namely, SS. Salvatore, was selected in order to apply the proposed methodology.

The SS. Salvatore church was built in 1541 at the will of Queen Sforza in the town centre of Capurso, located a few kilometres from Bari. Since it is typical Romanesque church, it exhibits a basilica-type plan, which is divided into three naves, a transept, an apse, a dome, and a bell tower (Figure 7a, b).

The church has experienced numerous geometrical and technical alterations over time, which have resulted in the present configuration. The most crucial variation was the replacement of the wood truss roof over the principal nave with a heavy reinforced concrete ceiling.

In fact, the church shows various signs of degradation due to atmospheric agents and the lack of maintenance. Therefore, the novel AHP-based procedure was employed to comprehensively
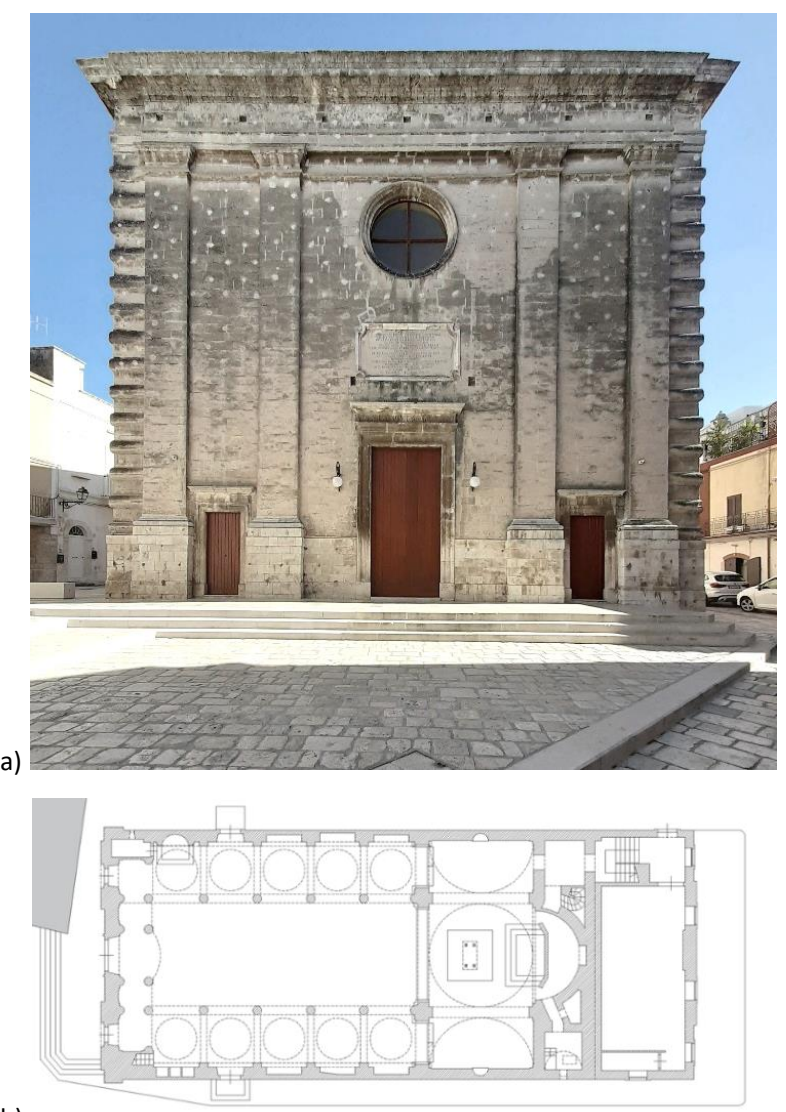

b)

Figure 7. The SS. Salvatore church: a) principal façade, b) church plan.
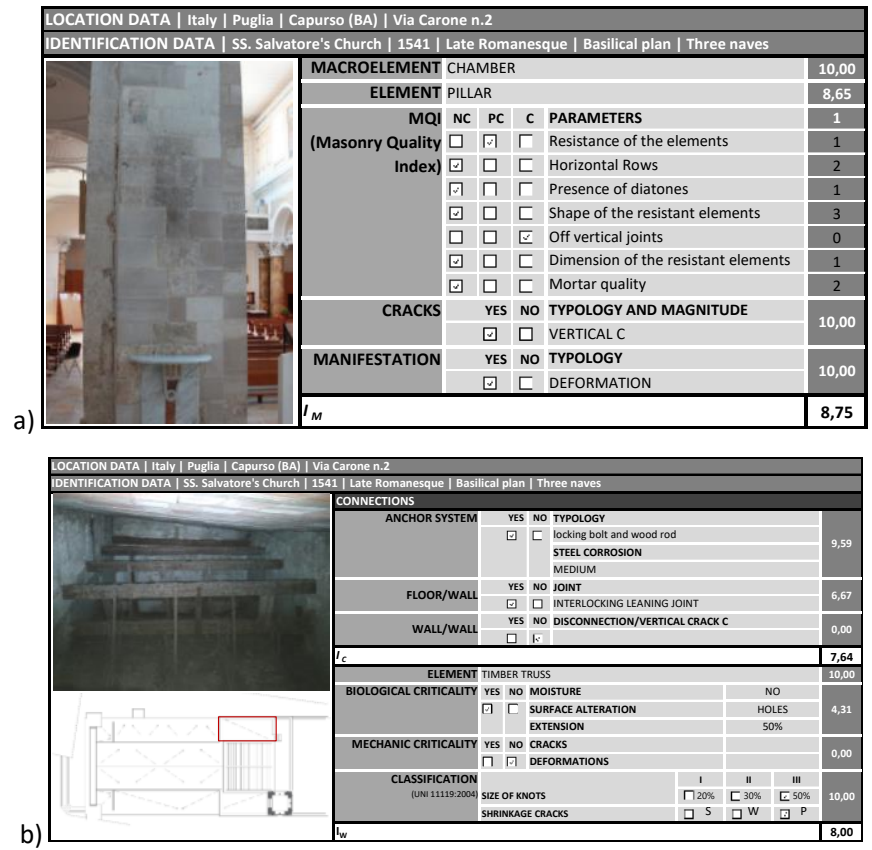

Figure 8. Survey forms for a) damaged pillar and b) damaged connection system.

investigate the church's pathologies and to quantify its criticalities.

The first step involved filling in the survey form in terms of any elements that appeared to be damaged. Figure 8 shows two examples of the survey form, one for the chamber pillar diagnostics (a) and one for the connection system of the bearing structure of the lateral transept vault (b).

Finally, an evaluation of the church's overall condition was carried out by calculating the global index (ISTRUCTURE) in terms of all the components of the structure. The result was 1.52 on a scale of $0-10$. This low result indicated that the general structural condition was good and that only minor damage had occurred. However, the survey form indices highlighted the dangerousness of the damages. Indeed, the $I_{M}$ (Figure $8 \mathrm{a}$ ) and $I_{C}$ (Figure $8 \mathrm{~b}$ ) values, which were over 7 on a scale of $0-10$, suggested the need for deeper investigations.

\section{VALIDATION}

A comparison of the results obtained via the proposed AHPbased method and those obtained via the traditional survey and diagnostics approach was conducted to validate the proposed approach for the Romanesque masonry church [1]-[38].

Here, various specialists, who did not know the results of the innovative approach, were involved in reporting on the condition of the SS. Salvatore church, performing a direct on-site inspection, creating technical plans of the church with the indications of damage marked, and compiling a report [39].

Following the technical description, it emerged that the pillars near to the dome presented the severest cracks and deformations, likely due to the heavy weight of the reinforced concrete roof covering the central nave. Thus, the conclusion was that these structures had been affected by compression damage.

The drawing shown in Figure 9, which was included in the specialists' technical sheets, indicates the cracking in red and clearly reveals the serious damage suffered by the pillars. 

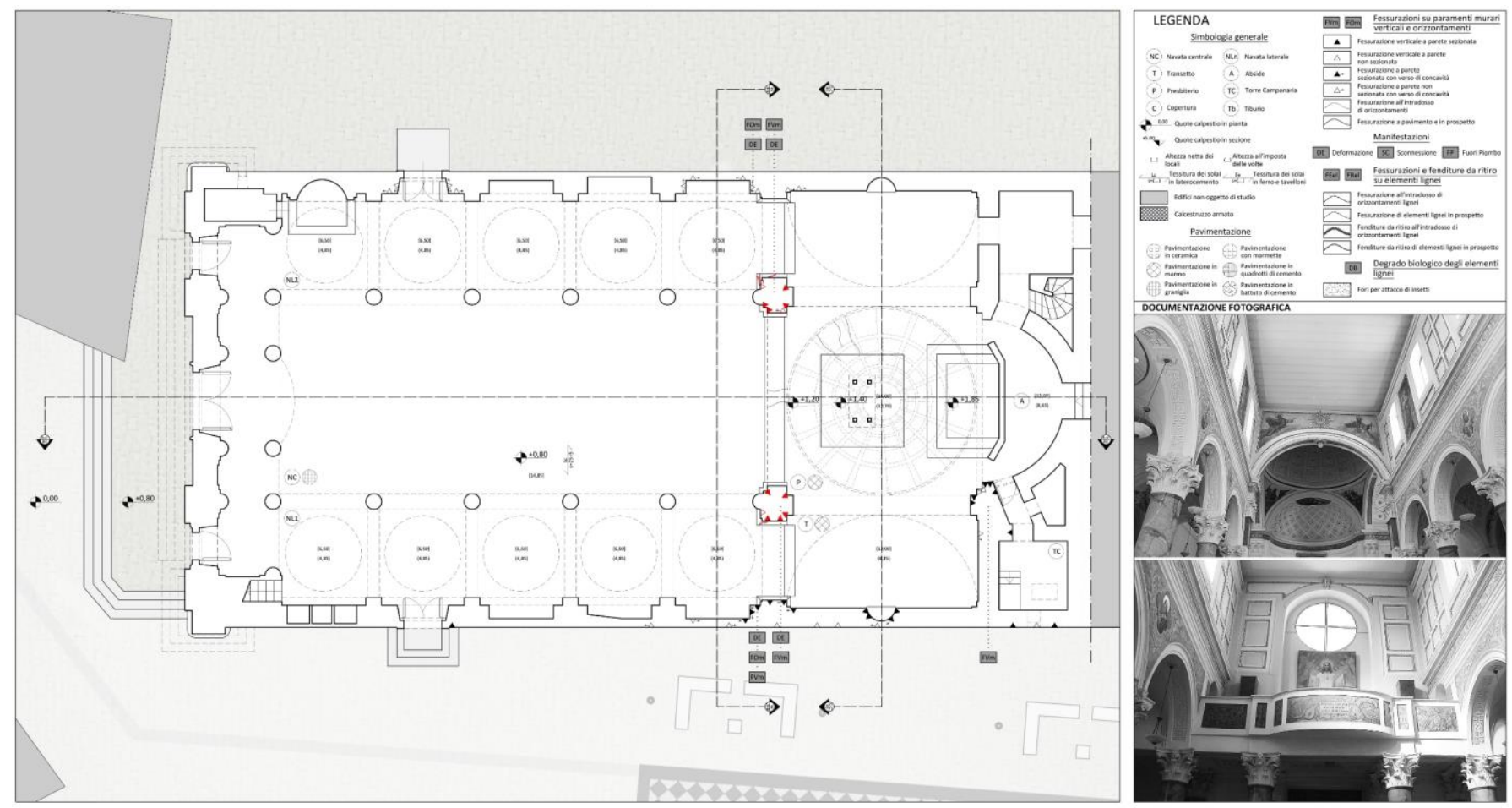

Figure 9. Technical drawing by specialists (with damage representation).

The comparison between the results of the two approaches revealed highly similar diagnoses. In short, all of the pathologies surveyed through the survey forms and quantified via the AHP approach agreed with the damage indicated by the traditional survey. Furthermore, the minor phenomena in the other structures were also comparable. Despite the similarity between the results, the AHP approach had the advantage of producing a numerical quantification of the criticalities, which would prove useful for comparing the damaged elements of the same structure or identifying buildings that are most at risk on a large scale. In addition, it allows for comparing different forms of damage on the same structure and provides support for planning more in-depth investigations such as destructive investigations.

Finally, this approach can be implemented in smart devices and a large-scale application information platform. In this field, the ratings of the specified conditions play a key role in the comparison between different structures and building types.

\section{CONCLUSIONS}

This article presented a new procedure based on the AHP approach, which was developed to perform rapid on-site measurements and diagnostics of masonry churches through a series of condition assessment indexes.

This approach could be implemented in conjunction with specific information technology to provide the advantages of simplicity, survey affordability, and knowledge of the survey's history through implementing the approach in a DSS. As such, the architecture of the DSS supported by an AHP-based diagnostics approach was specified in this work.

This methodology provides four innovative aspects of the visual diagnostics of masonry structures. First, the AHP approach allows for both qualitative and quantitative data to be included in the analysis, including in terms of connections, wood elements, and moisture.
Second, the proposed survey and diagnostics carried out with appropriate assessments of the conditions provides an extensive application for identifying buildings with the greatest amount of damage that require more detailed structural surveys.

Third, the AHP-based diagnostics combined with a DSS procedure provides a useful tool that allows for performing analyses on a regional scale. In fact, the DSS could detect the damaged elements of masonry churches under investigation using specific survey devices, such as thermal imaging cameras or ground-penetrating radar.

Finally, a comparison with a standard survey was carried out to validate the method and to underline the advantages of the attendant innovative diagnostics.

After discussing the method, a representative case study was selected to assess the proposed methodology. Here, the SS. Salvatore church in Capurso (near Bari) was chosen since it presented the typical religious architectural characteristics of the Apulian Romanesque style.

Here, a number of specialists performed a traditional survey, from which it was deduced that the pillars near the dome presented damage that was due to compression. A comparison of this result and the defined condition ratings was then carried out to validate the proposed procedure. Since the two approaches provided a comparable diagnosis, the innovative method was regarded as valid.

Since the proposed AHP-based approach has the advantage of obtaining numerical values for characterising the performance of the structure, it represents a promising tool for structural monitoring and diagnosis.

Future research will focus on a large-scale application of the proposed methodology to demonstrate the potential of the proposed DSS for monitoring and diagnosing masonry structures. 


\section{REFERENCES}

[1] G. Uva, V. Sangiorgio, S. Ruggieri, F. Fatiguso, Structural vulnerability assessment of masonry churches supported by userreported data and modern Internet of Things (IoT), Measurement 131 (2019) pp.183-192.

DOI: $10.1016 /$ i.measurement.2018.08.014

[2] P. Fong, S. Choi, Final contractor selection using the analytical hierarchy process. Constr. Manage. Econ. 18(5) (2000) pp. 547 557.

DOI: $\underline{10.1080 / 014461900407356}$

[3] T. Y. Hsieh, S. T. Lu, G. H. Tzeng, Fuzzy MCDM approach for planning and design tender selection in public office buildings, Int. J. Project Manage. 22(7) (2004) pp. 573-584.

DOI: $10.1016 /$ i.iproman.2004.01.002

[4] E. Plebankiewicz, D. Kubek, Multicriteria selection of the building material supplier using AHP and fuzzy AHP, J. Constr. Eng. Manage. (2015), p. 04015057.

DOI: $10.1061 /(\mathrm{ASCE}) \mathrm{CO} .1943-7862.0001033$

[5] C. Kahraman, U. Cbeci, Z. Ulukan, Multi-criteria supplier selection using fuzzy AHP, Logist. Inf. Manage. 16(6) (2003) pp. 382-394.

DOI: $10.1108 / 09576050310503367$

[6] J. K. Wong, H. Li, Application of the analytic hierarchy process (AHP) in multicriteria analysis of the selection of intelligent building systems, Build. Environ., 43(1) (2008) pp. 108-125. DOI: $10.1016 /$ j.buildenv.2006.11.019

[7] S. Kwon, G. Lee, D. Ahn, H. S. Park, A modified-AHP method of productivity analysis for deployment of innovative construction tools on construction site, J. Constr. Eng. Project Manage. 4(1) (2014) pp. 45-50.

DOI: $\underline{10.6106 / J C E P M .2014 .4 .1 .045 ~}$

[8] A. Shapira, M. Goldenberg, AHP-based equipment selection model for construction projects, J. Constr. Eng. Manage. 10.1061 /(ASCE)0733-9364(2005)131:12(1263) (2005) pp. 1263-1273. DOI: 10.1061/(ASCE)0733-9364(2005)131:12(1263)

[9] B. Reza, R. Sadiq, K. Hewage, Sustainability assessment of flooring systems in the city of Tehran: An AHP-based life cycle analysis, Constr. Build. Mater. 25(4) (2011) pp. 2053-2066. DOI: $10.1016 /$ j.conbuildmat.2010.11.041

[10] K. F. Chang, C. M. Chiang, P. C. Chou, Adapting aspects of GBTool 2005-Searching for suitability in Taiwan, Build. Environ. 42(1) (2007) pp. 310-316. DOI: $10.1016 /$ i.buildenv.2005.08.015

[11] E. A. L. Teo, F. Y. Y. Ling, Developing a model to measure the effectiveness of safety management systems of construction sites, Build. Environ. 41(11) (2006) pp. 1584-1592. DOI: $10.1016 /$ i.buildenv.2005.06.005

[12] F. Li, K. K. Phoon, X. Du, M. Zhang, Improved AHP method and its application in risk identification, J. Constr. Eng.Manage. 10.1061/(ASCE)CO.1943-7862.0000605 (2013) pp. 312-320. DOI: $10.1061 /$ (ASCE)CO.1943-7862.0000605

[13] S. Das, M. Y. L. Chew, K. L. Poh, Multi-criteria decision analysis in building maintainability using analytical hierarchy process, Constr. Manage. Econ. 28(10) (2010) pp. 1043-1056.

DOI: $\underline{10.1080 / 01446193.2010 .501806}$

[14] S. Wu, A. Lee, J. H. M. Tah, G. Aouad, G. The use of a multiattribute tool for evaluating accessibility in buildings: The AHP approach, Facilities 25(9-10) (2007) pp. 375-389.

DOI: $10.1080 / 01446193.2010 .501806$

[15] M. Kettner, J. Diaz, Document management in building authorities with the aid of a workflow management system, 8th Int. Conf. on Computing in Civil and Building Engineering, ASCE, Reston, VA, 2000, pp. 1102-1109.

DOI: $10.1061 / 40513(279) 143$

[16] H. H. Ali, S. F. Al Nsairat, Developing a green building assessment tool for developing countries-Case of Jordan, Build. Environ. 44(5) (2009) pp. 1053-1064.

DOI: $10.1016 /$ j.buildenv.2008.07.015
[17] E. Gigliarelli, L. Cessari, A. Cerqua, Application of the analytic hierarchy process (AHP) for energetic rehabilitation of historical buildings, $1^{1 \text { th }}$ Int. Symp. on the AHP, Creative Decision Foundation, Sorrento, Italy, 15-18 June 2011, pp. 1-6.

DOI: 10.13033 /isahp.y2011.135

[18] E. Wang, Z. Shen, J. Neal, J. Shi, C. Berryman, A. Schwer, An AHP-weighted aggregated data quality indicator (AWADQI) approach for estimating embodied energy of building materials, Int. J. Life Cycle Assess. 17(6) (2012) pp. 764-773. DOI: $10.1007 / \mathrm{s} 11367-012-0417-8$

[19] R. Aghataher, M. R. Delavar, M. H. Nami, N. Samnay, A fuzzyAHP decision support system for evaluation of cities vulnerability against earthquakes, World Appl. Sci. J. 3(1) (2008) pp. 66-72.

[20] B. Faggiano, A. Formisano, D. De Gregorio, T. De Lucia, F.M. Mazzolani, A quick level methodology for the volcanic vulnerability assessment of buildings, Appl. Mech. Mater. 82 (2011) pp. 639-644.

DOI: $10.4028 /$ www.scientific.net/AMM.82.639

[21] A. Formisano, F.M. Mazzolani, On the selection by MCDM methods of the optimal system for seismic retrofitting and vertical addition of existing buildings, Comput. Struct. 159(1) (2015) pp. $1-13$. DOI: $10.1016 /$ j.compstruc.2015.06.016

[22] P. Benítez, E. Rocha, H. Varum, F. Rodrigues, A dynamic multicriteria decision-making model for the maintenance planning of reinforced concrete structures, Journal of Building Engineering 27 (2020) p. 100971.

DOI: $10.1016 /$ j.jobe.2019.100971

[23] V. Sangiorgio, S. Martiradonna, G. Uva, F. Fatiguso, An information system for masonry building monitoring, IEEE International Conference on Service Operations and Logistics, and Informatics, SOLI 2017, Bari, Italy, 2017, pp. 230-235. DOI: $\underline{\text { 10.1109/SOLI.2017.8120999 }}$

[24] V. Totaro, A. Gioia, V. Iacobellis, Numerical investigation on the power of parametric and nonparametric tests for trend detection in annual maximum series, Hydrol. Earth Syst. Sci. 24 (2020) pp. 473-488. DOI: $\underline{10.5194 / \text { hess-24-473-2020 }}$

[25] G. Balacco, V. Totaro, A. Gioia, A.F. Piccinni, Evaluation of geomorphic descriptors thresholds for flood prone areas detection on ephemeral streams in the metropolitan area of Bari, 19th International Conference on Computational Science and Its Applications, ICCSA 2019, Saint Petersburg, Russian Federation, 2019, pp. 239-254. DOI: $10.1007 / 978-3-030-24305-0 \quad 19$

[26] V. Dorokhov, N. Pintelin, Control of temperature and humidity conditions of church buildings-architectural monuments as a method of preservation, IOP Conference Series: Materials Science and Engineering, Vladivostok, Russian Federation, 2018, p. 032076.

[27] J. Shah, B. Mishra, Customized IoT enabled wireless sensing and monitoring platform for preservation of artwork in heritage buildings, 2016 IEEE International Conference on Wireless Communications, Signal Processing and Networking, WiSPNET 2016, Chennai, India, 2016, pp. 361-366.

DOI: $10.1016 /$ i.protcy.2016.03.025

[28] F.J. Mesas-Carrascosa, D. Verdú Santano, J.E.M. de Larriva, R. Ortíz Cordero, R.E. Hidalgo Fernández, A. García-Ferrer, Monitoring heritage buildings with open source hardware sensors: a case study of the mosque-cathedral of Córdoba, Sensors 16(10) (2016) p. 1620. DOI: $10.3390 / \mathrm{s} 16101620$

[29] C. Scuro, P.F. Sciammarella, F. Lamonaca, R.S. Olivito, D.L. Carni, Io'T for structural health monitoring, IEEE Instrumentation and Measurement Magazine 21(6) (2018) pp. 414. DOI: $10.1109 /$ MIM.2018.8573586

[30] S. Martiradonna, I. Lombillo, F. Fatiguso, Performance monitoring of refurbished building through innovative precast concrete modules, IEEE International Conference on Systems, 
Man and Cybernetics, SMC 2019, Bari, Italy, 2019, pp. 953-957 DOI: $10.1109 /$ SMC.2019.8914472

[31] T. L. Saaty, Decision making with the analytic hierarchy process, Int. J. Services Sci. 1(1) (2008) pp. 83-98. DOI: $10.1504 /$ IJSSci.2008.01759

[32] V. Sangiorgio, G. Uva, J. M. Adam, Integrated seismic vulnerability assessment of historical masonry churches including architectural and artistic assets based on macro-element approach. International Journal of Architectural Heritage (2020) pp. 1-14. DOI: $10.1080 / 15583058.2019 .1709916$

[33] E. E. Noble, P. P. Sanchez, A note on the information content of a consistent pairwise comparison judgment matrix of an AHP decision maker, Theory Decision 34(2) (1993) pp. 99-108. DOI: $10.1007 /$ BF01074896

[34] A. Borri, R. Sisti, G. Castori, M. Corradi, A. De Maria, Analysis of the collapse mechanisms of three churches in valnerina struck by the 2016 Italian earthquake, International Journal of Architectural Heritage 13 (2019) pp. 17-21. DOI: $10.1080 / 15583058.2018 .1431731$

[35] V. Sangiorgio, G. Uva, F. Fatiguso, User-reporting based semeiotic assessment of existing building stock at the regional scale, Journal of Performance of Constructed Facilities 32(6)
(2018) p. 04018079

DOI: $10.1061 /$ (ASCE)CF.1943-5509.0001227

[36] V. Sangiorgio, G. Uva, F. Fatiguso, A procedure to assess the criticalities of structures built in absence of earthquake resistant criteria, REHABEND 2016, Burgos, Spain, 2016, pp. 631-639.

[37] V. Sangiorgio, G. Uva, F. Fatiguso, Development of an innovative quality detection platform for reinforced concrete school buildings: An app for large scale supervising, The New Boundaries of Structural Concrete, Capri, Italy, 29 September-1 October 2016, pp. 201-211.

DOI: $10.1109 /$ SOLI.2017.8120999

[38] L. Binda, A. Saisi, C. Tiraboschi, Investigation procedures for the diagnosis of historic masonries, Construction and Building Materials 14(4) (2000) pp. 199-233. Online [Accessed 22 March 2021] http://hdl.handle.net/11311/501569

[39] M. P. Schuller, Non-destructive testing and damage assessment of masonry structures, Progress in Structural Engineering and Materials 5(4) (2003) pp. 239-251

DOI: $\underline{10.1002 / p s e .160}$ 